\title{
Induction of oral tolerance and the effect of interleukin-4 on murine skin allograft rejection
}

\section{A.L.A. Dettino, \\ A.J.S. Duarte \\ and M.N. Sato}

Laboratório de Alergia e Imunologia Clínica e Experimental, LIM-56, Faculdade de Medicina, Universidade de São Paulo, São Paulo, SP, Brasil

\section{Correspondence}

M.N. Sato

Laboratório de Alergia e Imunologia

Clínica e Experimental, LIM-56

Faculdade de Medicina, USP

Av. Dr. Arnaldo, 455, Sala 2345

01246-903 São Paulo, SP

Brazil

Fax: +55-11-3081-7190

E-mail: marisato@usp.br

Presented at the I Symposium on

Advances in Medical Research,

Institute of Medical Investigation

Laboratories, HC-FMUSP, São Paulo,

SP, Brazil, March 21-22, 2003.

Research supported by FAPESP

and LIM-56, HC/FMUSP.

Received June 12, 2003

Accepted November 4, 2003

..................

\begin{abstract}
We studied the effect of oral and portal vein administration of alloantigens on mouse skin allograft survival. Graft receptor BALB/c mice received spleen cells $\left(30,90,150\right.$ or $\left.375 \times 10^{6}\right)$ from donor C57BL/6 mice intragastrically on three successive days, starting seven days before the skin graft. Allograft survival was significantly increased with the feeding of $150 \times 10^{6}$ allogeneic spleen cells by one gavage (median survival of 12 vs 14 days, $\mathrm{P} \leq 0.005$ ) or when $300 \times 10^{6}$ cells were given in six gavage (12 vs 14 days, $\mathrm{P}<0.04)$. A similar effect was observed when $150 \times 10^{6}$ spleen cells were injected into the portal vein (12 vs 14 days, $\mathrm{P} \leq 0.03$ ). Furthermore, prolonged allograft survival was observed with subcutaneous (12 vs 16 days, $\mathrm{P} \leq 0.002)$ or systemic (12 vs 15 days, $\mathrm{P} \leq 0.016$ ) application of murine interleukin-4 (IL-4), alone or in combination with spleen cell injection into the portal vein (12 vs 18 days, $\mathrm{P} \leq 0.0018$ ). Taken together, these results showed that tolerance induction with spleen cells expressing fully incompatible antigens by oral administration or intraportal injection partially downmodulates skin allograft rejection. Furthermore, these findings demonstrated for the first time the effect of subcutaneous or systemic IL4 application on allograft skin survival suggesting its use as a beneficial support therapy in combination with a tolerance induction protocol.
\end{abstract}

\section{Introduction}

Oral administration of antigens induces peripheral immune tolerance and can suppress subsequent humoral and cellular responses to these same antigens (1). Induction of tolerance has good potential for treatment due to its specificity and to the reduction of the risks of undesirable side effects. It can be used to reduce allograft rejection as well as autoimmune and allergic experimental diseases $(2,3)$.

Several factors can influence oral toler-
Key words - Mouse oral tolerance

- Intraportal route

- Skin transplantation

- Interleukin-4

- Alloantigen ance, including age, genetically determined susceptibility, dose and time between oral antigen administrations $(4,5)$. The primary mechanisms involved in oral tolerance are clonal deletion, anergy and suppression (610). The antigen may stimulate cells from the gastrointestinal lymphoid tissue system to produce regulatory cytokines, such as transforming growth factor- $\beta$ (TGF- $\beta$ ), interleukin-10 (IL-10) and IL-4 (3). Induction of tolerance has also been observed when donor cells are injected into the portal vein, with prolongation of renal allograft survival 
(11). The effect of portal vein antigen injection on allogeneic graft acceptance in mice may involve $\gamma / \delta \mathrm{TCR}+$ producers of Th2 cytokines (12).

An important cell-mediated host response is produced during allograft rejection, involving macrophages, polymorphonuclear cells, CD8+ cells, and Th1 subtype CD4+ cells. These cells contribute to the inflammatory response by secreting cytokines. Since IL-4, a Th2 cytokine, has an important regulatory role, it could be involved in the modulation of skin graft rejection. However, no investigations have been carried out on how the local application of IL-4 affects skin allograft survival.

We determined the effect of the oral administration of various doses of spleen cells from fully incompatible donors and of donor cell injection into the portal vein on skin graft rejection in mice. Additionally, the effect of subcutaneous ( $s c$ ) and intraperitoneal (ip) administration of IL-4 on skin graft rejection was measured, associated or not with the injection of allogeneic spleen cells via the portal vein.

\section{Material and Methods}

\section{Animals}

Seven- to twenty-week-old male C57BL/ 6 mice served as donors and male BALB/c mice of the same age as recipients of the skin grafts. The animals were provided by the animal facility of the University of São Paulo Medical School and kept under controlled light and temperature in our own facilities. The animals received standard laboratory diet (Purina, Campinas, SP, Brazil) and water ad libitum.

\section{Skin graft}

Full-thickness skin grafts were harvested from the dorsum of $\mathrm{C} 57 \mathrm{BL} / 6$ mice and grafted onto the backs of $\mathrm{BALB} / \mathrm{c}$ mice using the technique of Billingham and Medawar (13). Each graft was sutured into place using 4-0 Mononylon ${ }^{\circledR}$ thread and protected with Brown's dressing for five days. The grafts were evaluated daily and scored as having been rejected when more than $90 \%$ of the grafted skin was visibly inviable. Groups of mice receiving isografts were also assessed daily.

\section{Spleen cell harvest}

Spleens from C57BL/6 mice were collected aseptically pressed through a stainless steel wire screen in RPMI-1640 culture medium (Gibco BRL, Gaithersburg, MD, USA), and erythrocytes were removed by hypotonic shock. The cells were washed twice and their concentration and viability determined.

\section{Oral and intraportal administration of spleen cells}

Groups of anesthetized mice were fed intragastrically using a urethral tube 30,90 , 150 or $375 \times 10^{6} \mathrm{C} 57 \mathrm{BL} / 6$ spleen cells on three consecutive days, starting seven days before the allograft. Other groups of mice also received intragastrically $300 \times 10^{6}$ cells divided into six doses on the 7th, 6th and 5th days before the graft and on the 7th, 8th and 9th days after the graft, or were treated with $300 \times 10^{6}$ cells divided into six doses on the 7 th, 6th and 5th days before the graft and on the 3rd, 4th and 5th days after the graft. Other graft recipient mice were injected once with $150 \times 10^{6}$ spleen cells into the portal vein seven days before the allograft.

\section{Recombinant IL-4 treatment protocol}

Allografted mice were injected $s c$ with 300 ng murine recombinant IL-4 (rIL-4; Pharmingen, San Diego, CA, USA) on the day of the skin graft (0) and on the 3rd, 5th and 7th 
days after grafting or by ip injections of 300 ng rIL-4 on days $0,3,5$ and 7 after grafting. Other groups of mice received $i p$ injections of $300 \mathrm{ng}$ rIL-4 and $150 \times 10^{6}$ donor spleen cells via the portal vein.

\section{Statistical analysis}

The overall survival curves were evaluated by the Kaplan Maier test and comparison between survival curves was performed by the Log rank test. Data are reported as median survival.

\section{Results}

\section{Effect of oral alloantigen administration on skin graft rejection}

Varying doses of splenocytes from skin graft donor $\mathrm{C} 57 \mathrm{BL} / 6$ mice were administered orally to $\mathrm{BALB} / \mathrm{c}$ mice. Recipient mice were fed intragastrically a total of 30,90 or $150 \times 10^{6}$ spleen cells from C57BL/6 mice, divided evenly among three successive days, seven days before the skin graft. Figure 1 shows that feeding $150 \times 10^{6}$ splenocytes significantly increased allograft survival (median survival, 14 days) compared to the allograft control group (12 days, $\mathrm{P} \leq$ $0.005)$.

To investigate the influence of dose and time of antigen delivery on allograft rejection, $300 \times 10^{6}$ spleen cells were administered intragastrically, $50 \times 10^{6}$ cells per day, 7, 6 and 5 days before the graft and $50 \times 10^{6}$ cells per day, 7, 8 and 9 days after graft (Figure 2). This procedure did not modify the course of graft rejection. However, when the second series was administered 3,4 and 5 days after the graft, there was a significant $(\mathrm{P} \leq 0.04)$ increase in graft survival (Figure 2). In contrast, a similar total dose of $375 \mathrm{x}$ $10^{6}$ cells administered as a single dose did not produce a significant change in the rate of graft rejection (8.5 days) compared to control (12 days).

\section{Effect of the administration of donor} splenocytes via the portal vein on skin graft rejection

Another group of allografted mice received $150 \times 10^{6}$ splenocytes via the portal

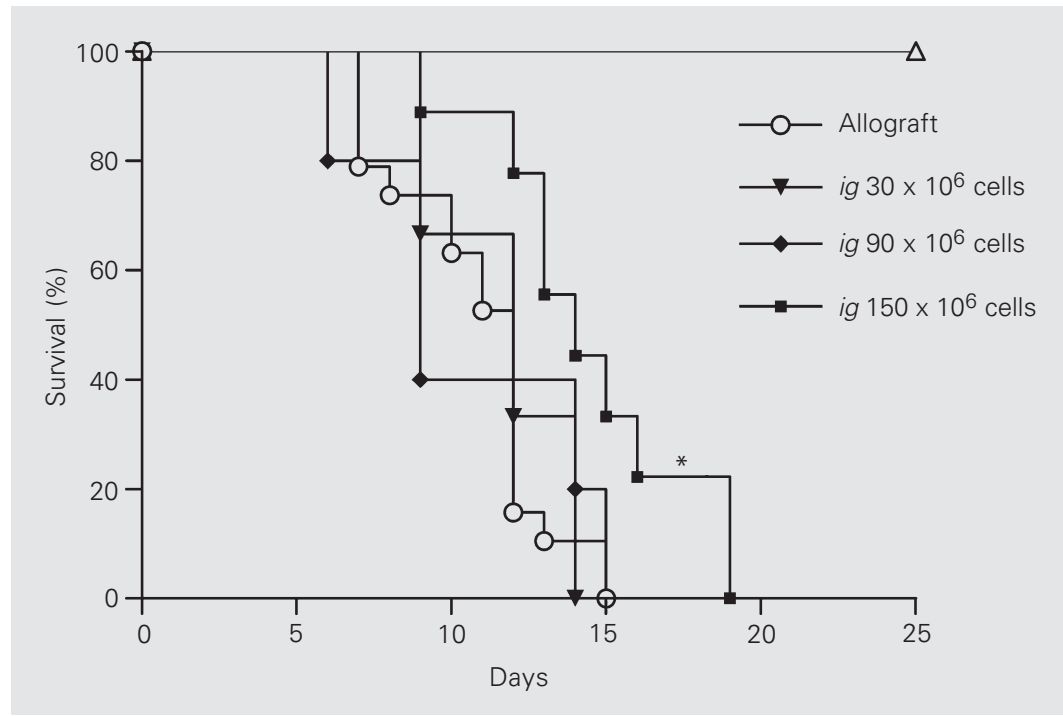

Figure 1. Effect of oral administration of donor splenocytes on skin allograft rejection. Splenocytes from skin graft donor C57BL/6 mice were administered by the intragastric (ig) route with $30 \times 10^{6}(\mathrm{~N}=6), 90 \times 10^{6}(\mathrm{~N}=5)$ or $150 \times 10^{6}$ cells $(\mathrm{N}=9)$. The control allograft alone with no allogeneic cells $(N=21)$ and isograft $(N=5)$ groups are shown. ${ }^{*} P \leq 0.005$ compared to the survival curve of the allograft group (Log rank test).

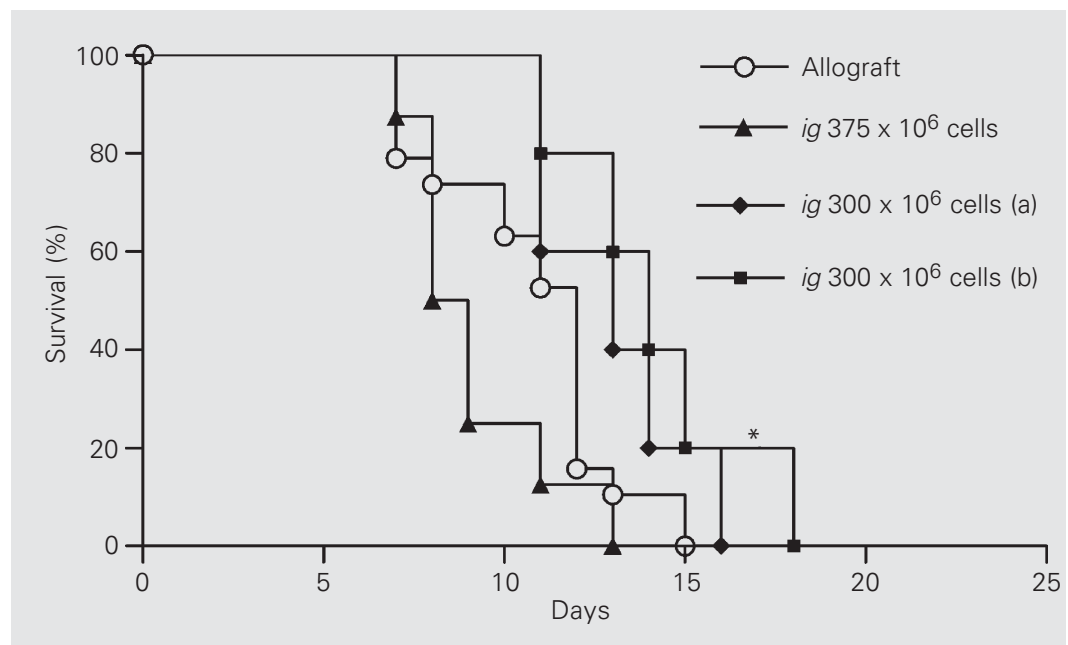

Figure 2. Effect of dose and antigen timing on skin allograft rejection. Recipient mice received by the intragastric (ig) route a total of $375 \times 10^{6}$ donor cells $(N=7)$ or a) $300 \times 10^{6}$ cells divided into six doses $(7,6$ and 5 days before the graft and 7,8 and 9 days after the graft, $N=5)$, or b) $300 \times 10^{6}$ cells graft divided into six doses $(7,6$ and 5 days before the graft and 3,4 and 5 days after the graft, $N=5$ ). ${ }^{*} P \leq 0.04$ compared to the survival curve of the allograft group (Log rank test). 
vein. Graft rejection in this group began later (on day 13) than in the control group (day 7) and graft survival increased significantly $(\mathrm{P}$ $\leq 0.03$, Figure 3 ).

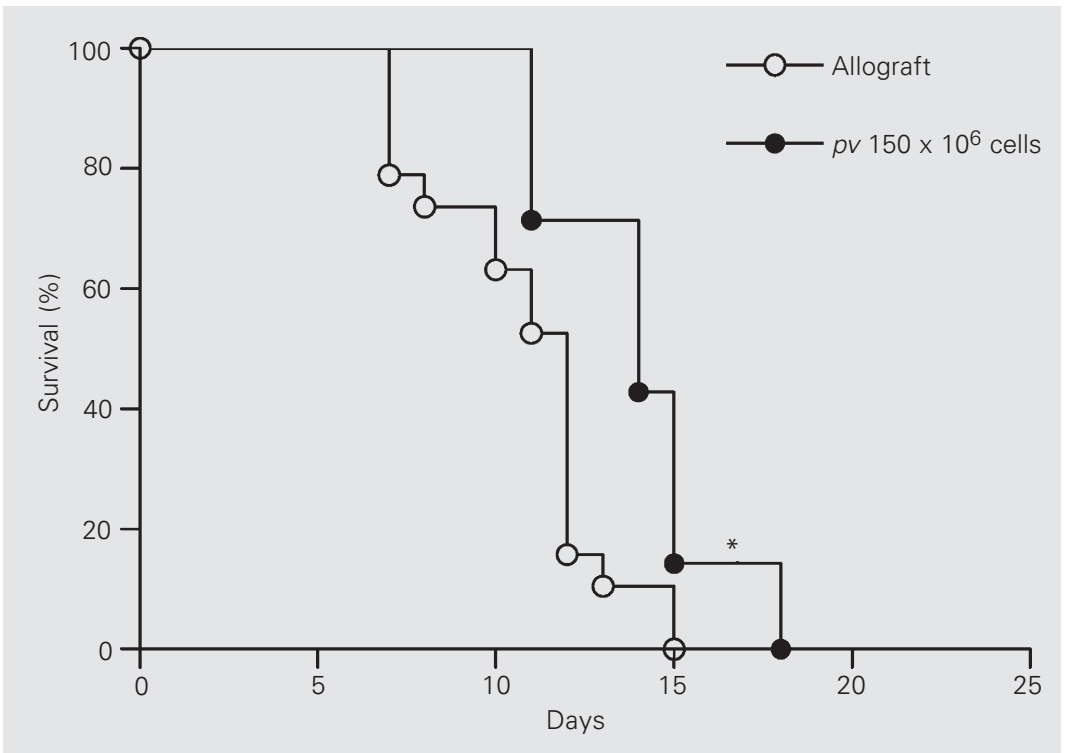

Figure 3. Effect of donor splenocyte injection via the portal vein on skin allograft rejection. Recipients received an injection of $150 \times 10^{6}$ spleen cells via the portal vein ( $p v$ ) seven days before allografting $(N=5)$. ${ }^{*} P \leq 0.03$ compared to the survival curve of the allograft group (Log rank test).

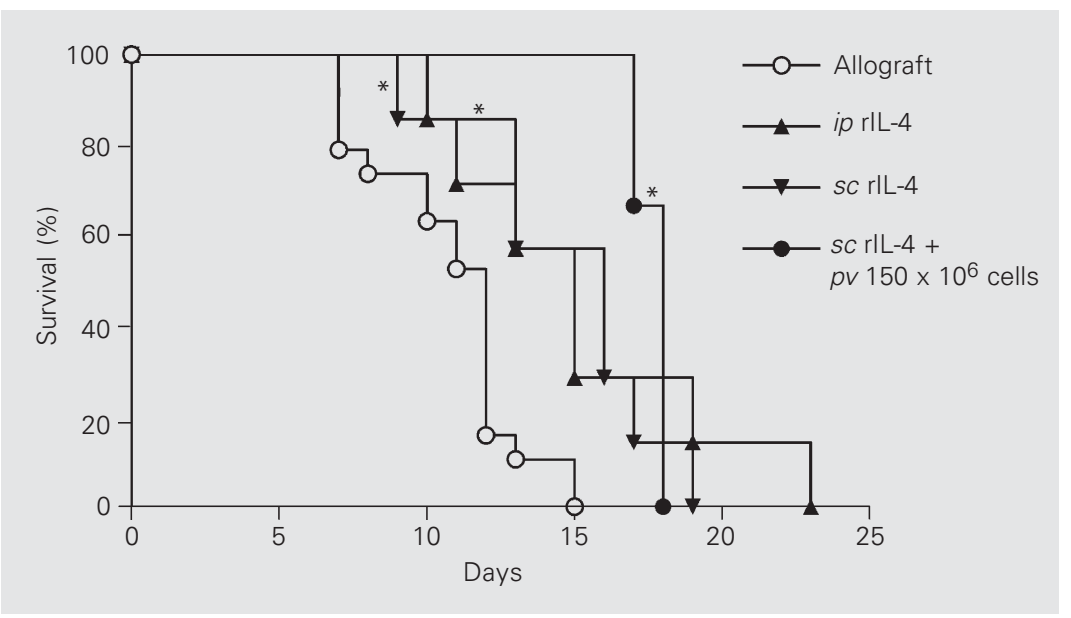

Figure 4. Effect of local or systemic application of rlL-4 on skin graft rejection. Allografted mice injected with rlL-4 subcutaneously $\left(s c, N=7,{ }^{*} P \leq 0.02\right.$ ) or intraperitoneally (ip, $N=$ 7, ${ }^{*} P \leq 0.002$ ) had increased graft survival compared to the allograft group (Log rank test). Other skin graft recipients $(N=3)$ were injected with $150 \times 10^{6}$ spleen cells into the portal vein $(p v)$ and $s c$ with rlL-4. ${ }^{*} P \leq 0.002$ compared to the survival curve of the allograft group (Log rank test).
Effect of local or systemic application of rIL-4 on skin graft rejection

Since Th1 response inflammatory cytokines are known to be secreted during the graft rejection process (10), we determined the effect of $300 \mathrm{ng}$ rIL-4 on the allograft by systemic or local administration. Groups of skin-grafted mice that received $400 \mathrm{ng}$ rIL-4 $s c$ in the skin graft (median survival, 16 days, $\mathrm{P} \leq 0.02$ ), or $300 \mathrm{ng}$ ip showed significantly increased graft survival ( 15 days, $\mathrm{P} \leq 0.002$ ) when compared to the saline-injected allograft control group (12 days) (Figure 4).

The $s c$ application of rIL-4 to the skin graft in combination with $150 \times 10^{6}$ splenocytes injected via the intraportal vein resulted in an increased allograft survival similar to that obtained with the application of rIL-4 alone (Figure 4).

\section{Discussion}

We investigated the effect of oral administration and portal vein injection of donor splenocytes on murine skin allograft rejection. We also evaluated the effect of local or systemic injection of rIL-4 on receptor allograft survival.

The efficiency of oral administration of donor splenocytes in prolonging graft survival was dose dependent. Feeding $150 \times 10^{6}$ cells increased allograft survival, while 375 $\mathrm{x} 10^{6}$ cells enhanced graft rejection. The partial modulation of graft survival could occur because fully mismatched allografts were employed; it is possible that longer graft survival would be obtained if there were only minor MHC disparities between the mouse strains. The alloantigen dose, the timing and the number of antigen administrations appear to be important factors in oral tolerance induction. This was evident and clearly shown by the fact that $375 \times 10^{6}$ cells administered on three consecutive days shortened graft survival, whereas a similar dose of $300 \times 10^{6}$ cells administered in six 
equal doses over a period of six days was able to prolong graft survival. Oral alloantigen administered continuously just after grafting was more effective than when administered one week after the graft. In another murine model of oral tolerance induction such as type I hypersensitivity to dust mite $(14,15)$, a dose-dependent effect on the modulation of the IgE response was observed in sensitized mice. An additional increase in the allergen dose enhanced the hypersensitivity response, worsening the allergic response $(14,15)$.

Similar to the effect obtained with antigen delivery to the mucosal site, injection of donor splenocytes into the portal vein prolonged skin allograft survival. The liver plays a critical role in oral tolerance, which may involve a loss of antigen-specific $\mathrm{T}$ cells after primary antigen injection, or hyporesponsiveness on reexposure to the antigen (16), due to the absence of co-stimulatory signals (17) or to defective antigen presentation by liver nonparenchymal cells (18). Prolonged allograft survival in mice by an impaired Th1 cytokine response, with a shift towards Th2 cytokine production has been described in mice injected with ovalbumin into the portal vein before transplantation (18). Antigen administration through the portal vein in an experimental colitis model stimulated liver-associated T NK1.1 lymphocytes with high serum IL-4 and TGF- $\beta 1$ and low IFN- $\gamma$ levels (19). Furthermore, IL12 in combination with anti-IL-10 reverses graft prolongation after portal venous immunization (3).

During the allogenic response the generation of IFN- $\gamma$-producing CD8 $+\mathrm{T}$ cells may skew both direct and indirect alloreactive responses towards the Th1 type. The modulation of allograft survival through tolerance could be mediated by down-regulation of pro-inflammatory Th1 cytokines, since tolerance to antigens induces Th2 cytokine production. The regulatory role of IL-4 in favoring a Th2 response by directly down-regulating the transcription factors promoting IFN$\gamma$ synthesis is well known (20). Our results demonstrated that rIL-4 injected $s c$ around the skin graft or even ip increased allograft survival, supporting the idea that IL-4 has a beneficial role in the initial allograft response. Injection of alloantigen through the portal vein associated with IL-4 treatment delayed the initial process of graft rejection, prolonged graft survival, but did not interfere with the final graft rejection process. It is possible that IL-4 regulates the initial alloresponse by modulating IFN- $\gamma$ activity in mismatched allografts, whereas it could have a different role in chronic rejection or in vascular grafts. Chronically rejected grafts have a marked accumulation of both IL-4 and IL5 mRNA (21), and the dominance of Th2 type cells apparently does not prevent cardiac allograft vasculopathy (22).

Oral administration or portal vein injection of splenic cells from fully incompatible donors retarded skin graft rejection. Local and systemic administration of rIL-4 to the skin graft receptor seems to be beneficial as a combined therapy in tolerance induction protocol.

\section{Acknowledgments}

We thank Maria Célia Rezende for animal care and Tathiana Pagano for the technical assistance.

\section{References}

1. Mowat AM (1987). The regulation of immune responses to dietary protein antigens. Immunology Today, 8: 93-98.

2. Sayegh MH, Khoury SJ, Hancock WW, Weiner HL \& Carpenter CB (1996). Mechanisms of oral tolerance by MHC peptides. Annals of the New York Academy of Sciences, 778: 338-345.

3. Weiner HL, Friedman A, Miller A, Khoury SJ, Al-Sabbagh A, Santos LMB, Sayegh M, Nussenblatt DE, Trentham DA \& Hafler DA (1994). Oral tolerance: immunologic mechanisms and treatment of animal 
and human organ-specific autoimmune diseases by oral administration of autoantigens. Annual Review of Immunology, 12: 809-837.

4. Chung $Y$, Chang S-Y \& Kang C-Y (1999). Kinetic analysis of oral tolerance: memory lymphocytes are refractory to oral tolerance. Journal of Immunology, 163: 3692-3698.

5. Faria AM, Garcia G, Rios MJ, Michalaros CL \& Vaz NM (1993). Decrease in susceptibility to oral tolerance induction and occurrence of oral immunization to ovalbumin in 20-38-week-old mice. The effect of interval between oral exposures and rate of antigen intake in the oral immunization. Immunology, 78: 147-151.

6. Friedman A \& Weiner HL (1994). Induction of anergy or active suppression following oral tolerance is determined by antigen dosage. Proceedings of the National Academy of Sciences, USA, 91: 6688-6692.

7. Khoury SJ, Hancoc W \& Weiner HL (1992). Oral tolerance to myelin basic protein and natural recovery from experimental autoimmune encephalomyelitis are associated with down-regulation of inflammatory cytokines and differential up-regulation of transforming growth factor- $ß$, interleukin-4 and prostaglandin $E$ expression in the brain. Journal of Experimental Medicine, 176: 1355-1364.

8. Melamed D, Fishman-Lovell J, Uni Z, Weiner HL \& Friedman A (1996). Peripheral tolerance of Th2 lymphocytes induced by continuous feeding of ovalbumin. International Immunology, 8: 717724.

9. Chen $Y$, Inobe I, Marks R, Gonella P, Kuchroo VK \& Weiner HL (1995). Peripheral deletion of antigen-reactive $T$ cells in oral tolerance. Nature, 376: 177-180.

10. Miller A, Lider O, Roberts AB, Sporn MB \& Weiner HL (1992). Suppressor $T$ cells generated by oral tolerization to myelin basic protein suppress both in vitro and in vivo immune responses by the release of transforming growth factor- $ß$ after antigen-specific triggering. Proceedings of the National Academy of Sciences, USA, 89: 421-425.

11. Carr RI, Zhou J, Ledingham D, Maloney C, McAlister V, Samson M, Bitter-Suermann H \& Lee TD (1996). Induction of transplantation tolerance by feeding or portal vein injection pretreatment of recipient with donor cells. Annals of the New York Academy of Sciences, 778: 368-370

12. Gorczynski RM, Chen Z, Hoang $Y$ \& Rossi-Bergman B (1996). A subset of gamma delta $T$-cell receptor-positive cells produce $\mathrm{T}$ - helper type-2 cytokines and regulate mouse skin graft rejection following portal venous pretransplant preimmunization. Immunology, 87: 381-389.

13. Billingham RE \& Medawar PB (1951). Technique of free skin grafting in mammals. Journal of Experimental Biology, 28: 385

14. Sato MN, Carvalho AF, Silva AO, Maciel Jr M, Fusaro AE \& Duarte AJS (1999). Low dose of antigen administered down regulates Th2 response in a murine model of hypersensitivity to house dust mite. Immunology, 98: 338-344.

15. Sato MN, Fusaro AE, Victor JR, Oliveira CR, Futata ET, Maciel M, Carvalho AF \& Duarte AJS (2001). Oral tolerance induction in Dermatophagoides pteronyssinus-sensitized mice induces inhibition of IgE-response and up-regulation of TGF- $ß$ secretion. Journal of Interferon and Cytokine Research, 21: 827-833.

16. Wrenshall LE, Ansite JD, Eckman PM, Heilman MJ, Stevens RB \& Sutherland DE (2001). Modulation of immune responses after portal venous injection of antigen. Transplantation, 71: 841-850.

17. Sugiura K, Kato K, Hashimoto F, Jin T, Amoh Y, Yamamoto Y, Morita H, Okumura K \& Ikehara S (1997). Induction of donor-specific T cell anergy by portal venous injection of allogeneic cells. Immunobiology, 197: 460-477.

18. Chen $Y$, Ong CR, McKenna GJ, Mui AL, Smith RM \& Chung SW (2001). Induction of immune responsiveness after portal vein immunization with ovalbumin. Surgery, 129: 66-75.

19. Trop S, Samsonov D, Gotsman I, Alper R, Diment J \& Ilan Y (1999). Liver-associated lymphocytes expressing NK 1.1 are essential for oral immune tolerance induction in a murine model. Hepatology, 29: 746-755.

20. Goenka S, Youn J, Dzurek LM, Schindler U, Yu-Lee LY \& Boothby M (1999). Paired Stat6 C-terminal transcription activation domains required both for inhibition of an IFN-responsive promoter and transactivation. Journal of Immunology, 163: 4663-4672.

21. Le Moine A, Flamand V, Demoor FX, Noel JC, Surquin M, Kiss R, Nahori MA, Petrolani M, Goldman M \& Abramowicz D (1999). Critical roles for $\mathrm{IL}-4, \mathrm{IL}-5$, and eosinophils in chronic skin allograft rejection. Journal of Clinical Investigation, 103: 1659-1667.

22. Hamano $K$, Bashuda $H$, Ito $H$, Shirasawa B, Okumura $K$ \& Esato $K$ (2000). Graft vasculopathy and tolerance: does the balance of Th cells contribute to graft vasculopathy? Journal of Surgical Research, 93: 28-34. 